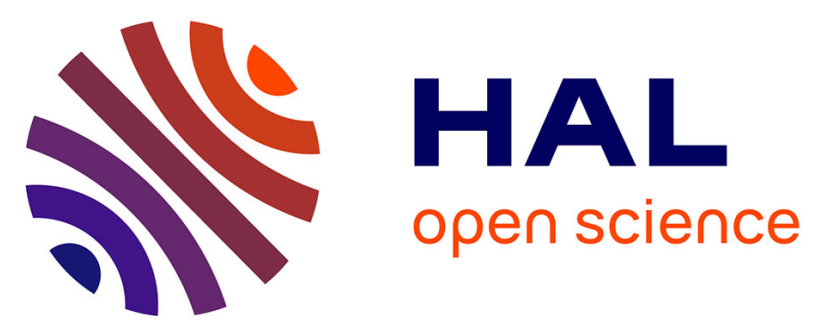

\title{
The relative contribution of river network structure and anthropogenic stressors to spatial patterns of genetic diversity in two freshwater fishes: A multiple-stressors approach
}

Jérôme Prunier, Vincent Dubut, Géraldine Loot, Loïc Tudesque, Simon

Blanchet

\section{To cite this version:}

Jérôme Prunier, Vincent Dubut, Géraldine Loot, Loïc Tudesque, Simon Blanchet. The relative contribution of river network structure and anthropogenic stressors to spatial patterns of genetic diversity in two freshwater fishes: A multiple-stressors approach. Freshwater Biology, 2018, 63 (1), pp.6 - 21. 10.1111/fwb.13034 . hal-01764118

\author{
HAL Id: hal-01764118 \\ https://hal.science/hal-01764118
}

Submitted on 11 Apr 2018

HAL is a multi-disciplinary open access archive for the deposit and dissemination of scientific research documents, whether they are published or not. The documents may come from teaching and research institutions in France or abroad, or from public or private research centers.
L'archive ouverte pluridisciplinaire $\mathbf{H A L}$, est destinée au dépôt et à la diffusion de documents scientifiques de niveau recherche, publiés ou non, émanant des établissements d'enseignement et de recherche français ou étrangers, des laboratoires publics ou privés. 


\title{
The relative contribution of river network structure and anthropogenic stressors to spatial patterns of genetic diversity in two freshwater fishes: A multiple-stressors approach
}

\author{
Jérôme G. Prunier ${ }^{1}$ (D) | Vincent Dubut ${ }^{2}$ | Géraldine Loot ${ }^{3,4}$ | Loïc Tudesque ${ }^{3,4}$ | \\ Simon Blanchet ${ }^{1,3}$
}

\begin{abstract}
${ }^{1}$ Station d'Écologie Théorique et Expérimentale (UMR 5371), Centre National de la Recherche Scientifique (CNRS), Université Paul Sabatier (UPS), Moulis, France

${ }^{2}$ Institut Méditerranéen de Biodiversité et d'Ecologie marine et continentale (UMR 7263), Aix Marseille Univ, CNRS, Institut de Recherche et du Développement, Avignon Univ, Marseille Cedex, France

${ }^{3}$ Laboratoire Evolution \& Diversité Biologique (UMR 5174), UPS, CNRS, Ecole Nationale de Formation Agronomique,

Toulouse Cedex, France

${ }^{4}$ UMR 5174 EDB (Laboratoire Évolution et Diversité Biologique), UPS, ENFA, Université de Toulouse, Toulouse Cedex, France
\end{abstract}

\section{Correspondence}

Jérôme G. Prunier, Station d'Écologie Théorique et Expérimentale (UMR 5371), Centre National de la Recherche Scientifique (CNRS), Université Paul Sabatier (UPS), Moulis, France.

Email: jerome.prunier@gmail.com

Funding information

Office Nationale de l'Eau et des Milieux Aquatiques (ONEMA)

\section{Abstract}

1. Recent findings highlighted the central role of the structure of the river network in shaping spatial patterns of genetic diversity in riverscapes. However, the influence of multiple anthropogenic stressors on these patterns may be just as important and the relative impacts of these two types of predictors have rarely been quantified simultaneously in river networks. Here, we contributed to filling this gap by investigating the relative contribution of both network structure and multiple anthropogenic stressors in shaping spatial patterns of genetic diversity in two freshwater fishes (Gobio occitaniae and Phoxinus phoxinus).

2. We focused on two rivers in which the two fish species were sampled along the upstream-downstream gradient. Microsatellite markers were used to quantify genetic diversity from three indices: allelic richness, private allelic richness and genetic uniqueness. Each sampling site was physically characterised according to its position in the network, and was described for multiple anthropogenic stressors including habitat degradation, fragmentation and stocking. This multiple-stressors approach was conducted using a fully explicit and generalisable analytical framework designed to cope with strong collinearity among environmental variables.

3. Overall, the contribution of network structure to the variance in genetic diversity was 1.8 times higher than the contribution of anthropogenic stressors. Both the position of sites along the upstream-downstream gradient and stocking were strong and consistent drivers of genetic variability. Conversely, the local influences of habitat degradation and fragmentation were species- and river-specific, sometimes even varying along the river channel, thus preventing any generalisations.

4. We concluded that the natural structure of networks and stocking strongly influence spatial patterns of genetic diversity in a predictable way, whereas the influence of other human activities may be much more difficult to predict over species and contexts.

\section{KEYWORDS}

commonality analysis, freshwater fish, landscape genetics, meta-analysis, stocking 


\section{INTRODUCTION}

Human activities are responsible for an unprecedented pace of environmental changes worldwide (Vitousek, Mooney, Lubchenco, \& Melillo, 1997), with high frequencies of recurrent biotic and abiotic stresses (sensu Borics, Várbíró, \& Padisák, 2013) such as habitat loss and landscape fragmentation, overexploitation of resources, pollutions, introduction of non-native species or climate change (Fahrig, 2003; Gurevitch \& Padilla, 2004; Halpern, Selkoe, Micheli, \& Kappel, 2007; McCarty, 2001). Understanding and predicting the impact of these stresses on biodiversity is essential for conservation planning, although this remains highly challenging. Anthropogenic stressors indeed act on all forms of biodiversity, that is, from individuals to ecosystems. Furthermore, they involve many interacting variables with complex additive, synergistic and antagonistic effects that are to be disentangled to allow appropriately set management plans and to generate reliable predictions (Christensen et al., 2006; Côté, Darling, \& Brown, 2016; Folt, Chen, Moore, \& Burnaford, 1999).

While multiple stressors have long been recognised as key factors influencing behavioural (e.g., Bonnot et al., 2013), physiological (e.g., Nacci, Gleason, \& Munns, 2002), morphological (e.g., Shinn, Blanchet, Loot, Lek, \& Grenouillet, 2015) or demographical (e.g., Dávalos, Nuzzo, \& Blossey, 2014) characteristics of populations, as well as community structure and ecosystem functioning (e.g., Connell, Hughes, \& Wallace, 1997; Nõges et al., 2016), their impacts on intraspecific genetic diversity are less well appreciated (Banks et al., 2013). Multiple stressors have direct and indirect impacts on main evolutionary forces shaping both neutral and adaptive genetic diversity (Hoffmann \& Willi, 2008). For instance, pollutants may directly affect mutation rates (e.g., Inostroza et al., 2016; Rogstad, Keane, \& Collier, 2003), decrease effective population size (Ribeiro \& Lopes, 2013), or induce directional selection on tolerant genotypes (Reid et al., 2016), whereas landscape degradation or fragmentation may affect both gene flow and genetic drift through the direct or indirect alteration of demographical processes such as mortality, recruitment, competition or dispersal (Banks et al., 2013; Manel, Schwartz, Luikart, \& Taberlet, 2003).

Studies investigating the influence of multiple stressors on patterns of genetic diversity usually take an evolutionary standpoint, focusing on the adaptive response of organisms to stresses through common garden experiments (e.g., Côté et al., 2016; Pini, Planes, Rochel, Lecchini, \& Fauvelot, 2011; Swindell, 2006) and, more recently, through population genomics and related methodologies such as genome-wide-association studies (Hand et al., 2016; Narum, Buerkle, Davey, Miller, \& Hohenlohe, 2013; Vandamme et al., 2014). Investigating the influence of multiple stressors on patterns of neutral genetic diversity in natural populations yet remains of prime importance to develop appropriate conservation strategies (Frankham, 2010; Paz-Vinas, Loot, Stevens, \& Blanchet, 2015; Pearse \& Crandall, 2004), but also to properly segregate patterns of adaptive genetic variation from those shaped by neutral processes in studies handling genomic data (Andrew et al., 2013; Banks et al., 2013).
Inhabiting highly constraining environments, freshwater species are confronted with multiple anthropogenic stressors (Dudgeon et al., 2006) that may interactively affect evolutionary processes such as gene flow and genetic drift. For instance, river fragmentation by weirs and dams can affect both gene flow and effective population sizes (Blanchet, Rey, Etienne, Lek, \& Loot, 2010; Faulks, Gilligan, \& Beheregaray, 2011; Raeymaekers et al., 2008). Human activities in the direct vicinity of local populations are also expected to influence patterns of genetic diversity through habitat degradation, over-harvesting of resources, stocking and/or introduction of non-native species (Allan, 2004; Laikre et al., 2010; Midway, Wagner, Tracy, Hogue, \& Starnes, 2015). In addition to these anthropogenic stressors, the natural topological characteristics of river networks are strongly shaping patterns of genetic variation (Altermatt, 2013). For instance, several studies reported a downstream increase in genetic diversity (DIGD), as well as an increase in allelic richness (AR) in highly connected demes in confluence zones (Paz-Vinas \& Blanchet, 2015; Paz-Vinas et al., 2015; Thomaz, Christie, \& Knowles, 2016). These recent studies highlight the combined effects of demes' location along the main channel, network dendricity and spatial heterogeneity in local carrying capacities along the upstream-downstream gradient on neutral genetic diversity.

In this study, we investigated the impacts of multiple natural features and anthropogenic stressors on spatial patterns of neutral genetic diversity and differentiation in two cyprinid fishes (the Eurasian minnow Phoxinus phoxinus and the Languedoc gudgeon Gobio occitaniae; Kottelat \& Persat, 2005) simultaneously sampled in two riverscapes. We specifically focused on natural features and anthropogenic stressors likely to influence major evolutionary processes (genetic drift, gene flow and genetic introgression), and we quantified the relative influence of each stressor. To that aim, we designed a novel analytical framework to synthesise a large number of variables into a few thematic predictors and assess their respective and interactive contributions to the variance in response variables while accounting for multicollinearity among predictors (Box 1). Thematic predictors were either related to natural features of the rivers (upstream-downstream gradient, local connectivity) or to anthropogenic stressors (fragmentation, habitat degradation and stocking). According to both theoretical expectations and empirical knowledge, we expected an increase in genetic diversity and a decrease in genetic differentiation along the main channel, particularly in highly connected demes (Paz-Vinas \& Blanchet, 2015; PazVinas et al., 2015). Conversely, we expected a decrease in genetic diversity and a possible increase in genetic differentiation with an increase in stream fragmentation (due to weirs and dams) and habitat degradation (due to water pollution and microhabitat alteration). Fragmentation is indeed expected to increase genetic drift and to decrease gene flow as it may both affect local carrying capacities and dispersal movements (e.g., Blanchet et al., 2010; Prunier, Dubut, Chikhi, \& Blanchet, 2017). Similarly, habitat degradation is likely to affect both effective population sizes through reproductive impairment and higher mortality rate (increase in genetic drift; e.g., Bickham, Sandhu, Hebert, Chikhi, \& Athwal, 2000) and gene flow 


\section{BOX 1}

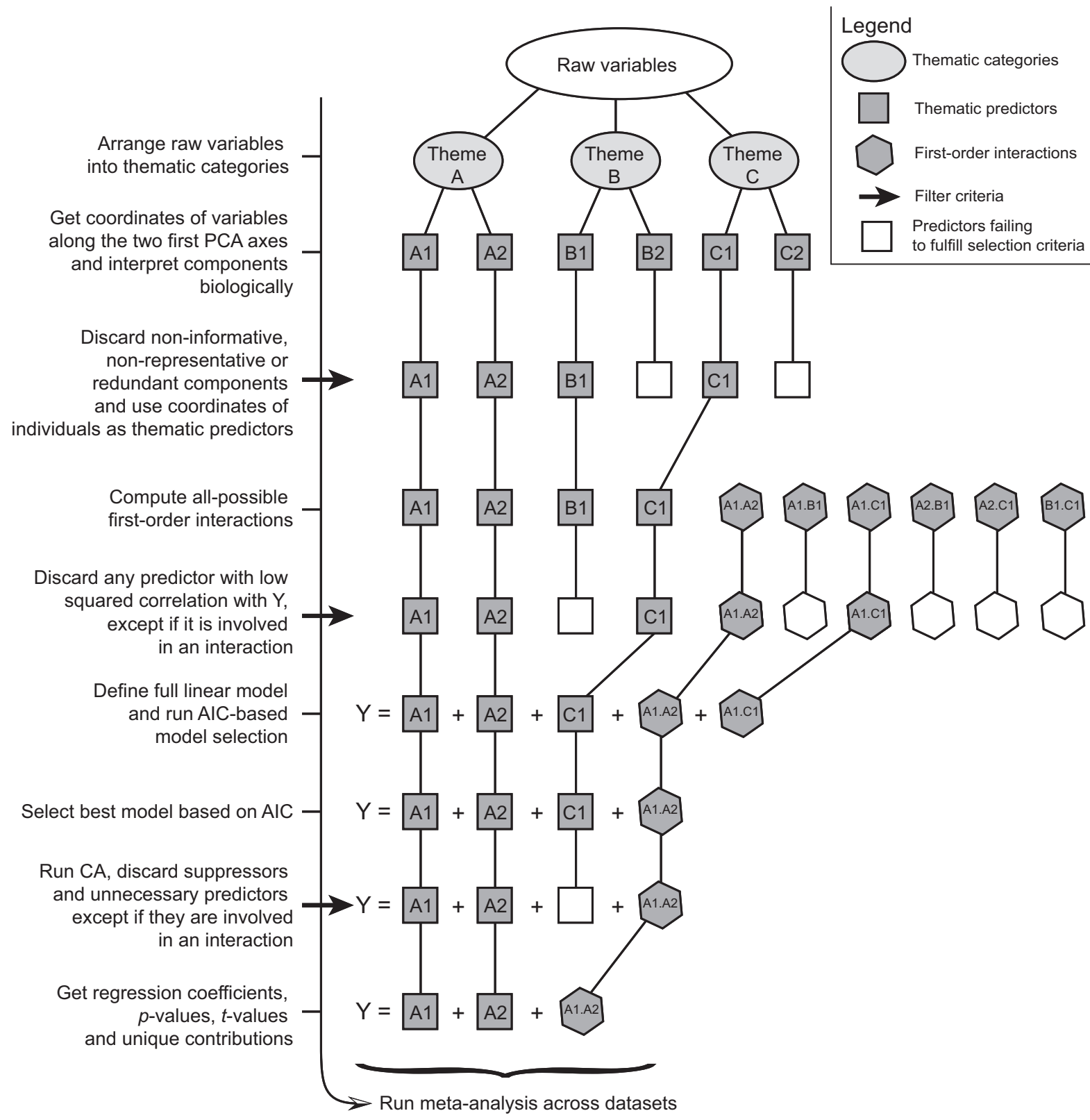

Flowchart of the analytical framework used in this study to handle a large number of interacting variables and cope with multicollinearity issues. Raw variables were synthesised into thematic predictors using principal component analyses, so that each predictor was both meaningful and valid across datasets. These thematic predictors were then filtered at three different steps through selection criteria intended (1) to discard non-informative, non-representative or redundant predictors, (2) to discard predictors explaining negligible amounts of variance in the dependent variable and thus likely to act as suppressors and (3) to discard any suppressor or unnecessary predictors retained in the course of AIC-based model selection.

patterns through isolation-by-environment, as individuals from high water/microhabitat quality may be reluctant to settle in stretches with different or lower water/microhabitat quality (e.g., Wang, 2013). We further expected both local changes in genetic diversity and a local increase in genetic differentiation in the presence of stocking, through genetic introgression from non-native individuals (Champagnon, Elmberg, Guillemain, Gauthier-Clerc, \& Lebreton, 2012; Laikre et al., 2010; Marie, Bernatchez, \& Garant, 2010). Finally, as the relative influence of stressors on biological dynamics depends on the intensity and frequency of their effects (Borics 
(a)

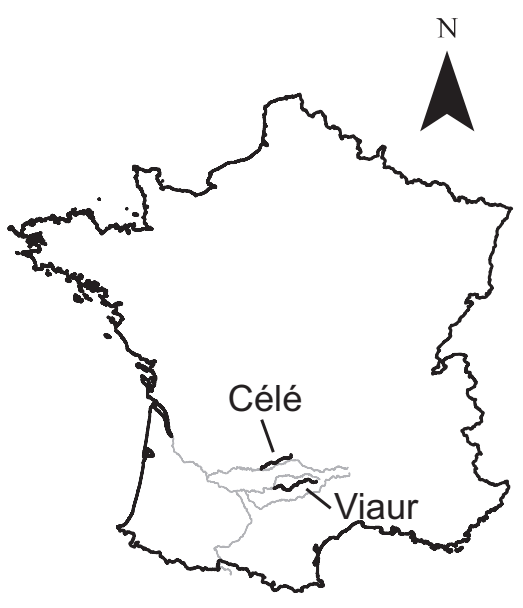

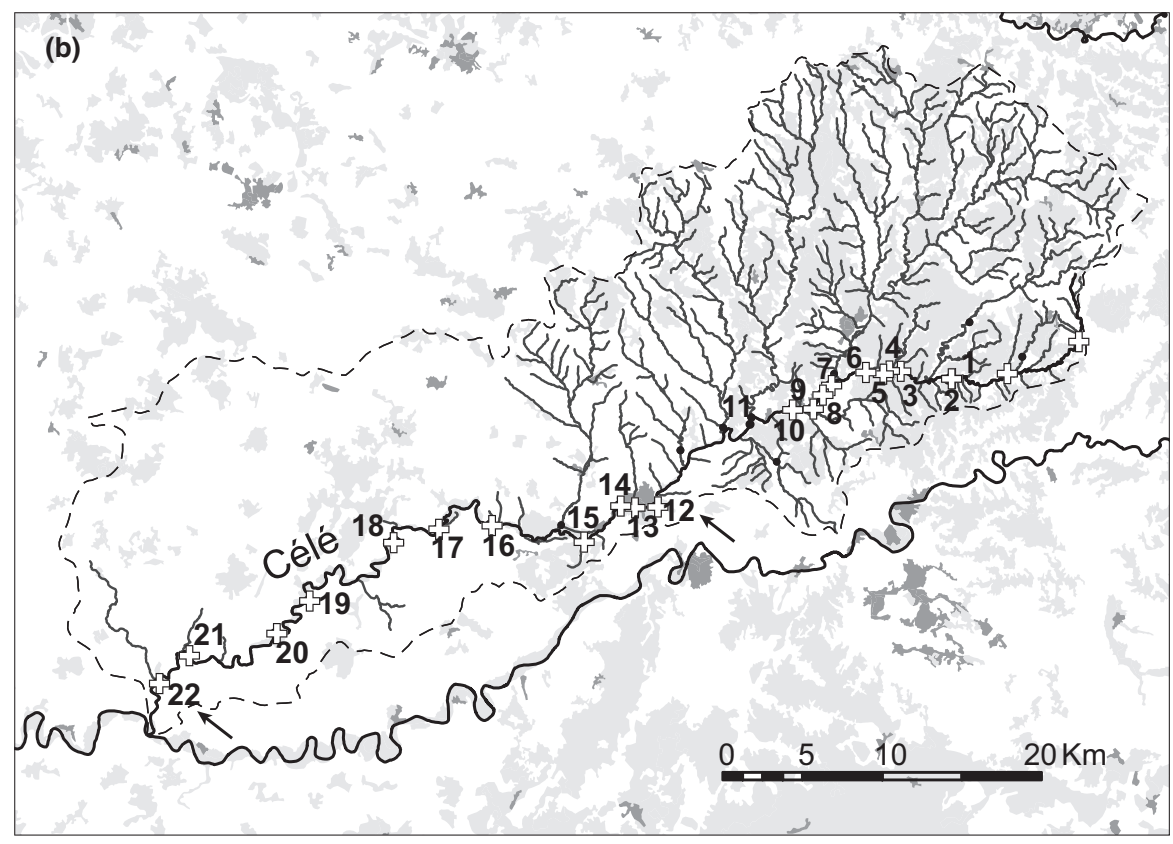

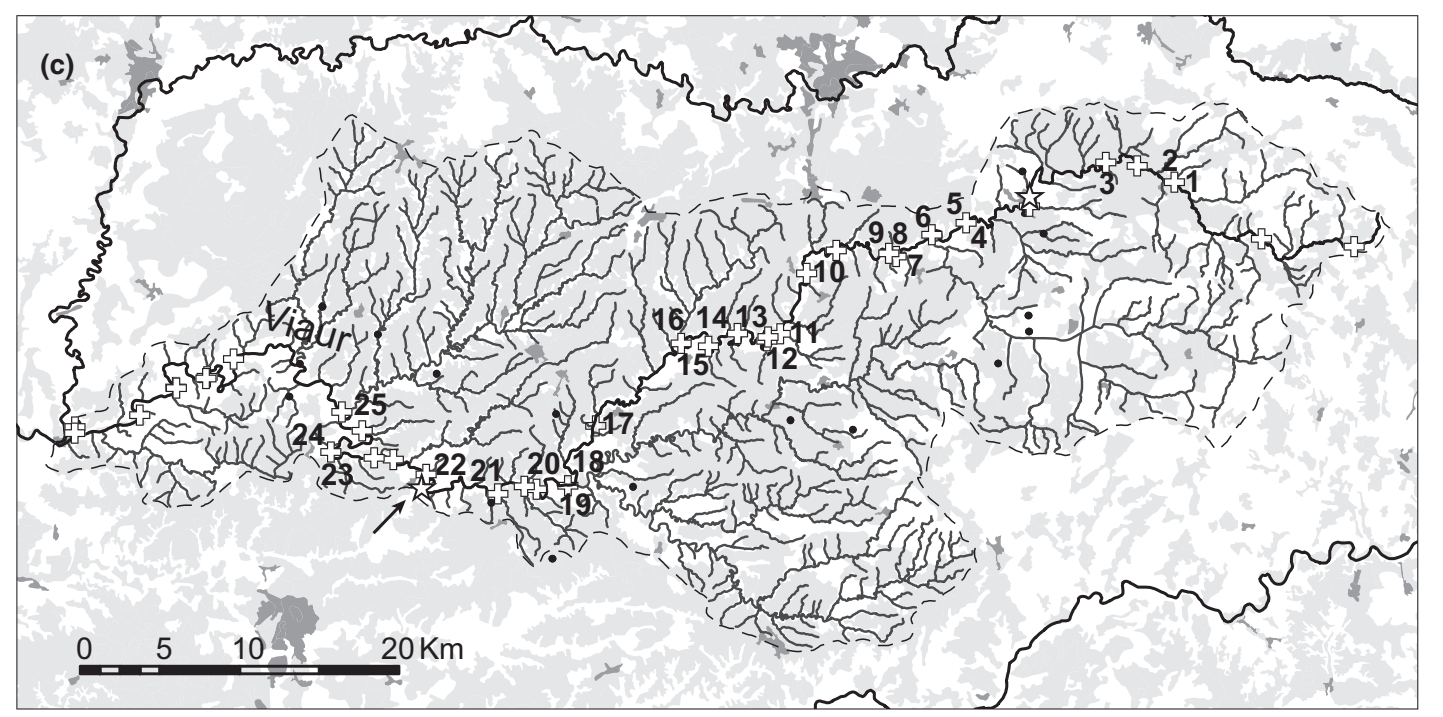

Legend:

17 Sampling sites

_ Main channels

_ Tributaries

- - - Limits of watersheds

Urban areas

Agricultural areas

Woods Meadows

乌 Weirs $(<3 \mathrm{~m})$

年 Dams (>30 m)

$\longrightarrow$ Stocking events

FIGURE 1 Main characteristics of the two studied systems: location of studied rivers in France (a), land cover, network topology and locations of sampled sites, of obstacles and stocking events along the Célé River (b) and the Viaur River (c)

et al., 2013), we expected long-term and more stable stressors such as fragmentation to have a higher relative influence on neutral genetic diversity than shorter-term and more punctual stressors such as habitat degradation. Overall-and for the same reasonsthe effects of anthropogenic stressors should be relatively weaker than natural features.

\section{METHODS}

\subsection{Study area and biological models}

The study was carried out in the Céle River and the Viaur River, both located in the Adour-Garonne river drainage in Southwestern
France (Figure 1a). Both drainage basins are of similar area $(1,350$ and $1,530 \mathrm{~km}^{2}$, respectively) and both rivers are of comparable length (136 and $168 \mathrm{~km}$, respectively). Nevertheless, both rivers differ in terms of network topology, fragmentation and land use within their basins. The Célé River is characterised by a large amount of branching (and thus complexity) in the upstream half part of the main channel and by a very simple topology in its downstream part (Figure 1b). The main channel is also weakly fragmented, with 22 identified weirs ( $<3 \mathrm{~m}$ high), most of the highest ones (2-3 m high) being equipped with fish ladders allowing fish crossing. Furthermore, only $19.5 \%$ of the Célé River drainage basin is mainly composed of urban and agricultural areas in its upstream half part. On the contrary, the Viaur River is characterised by a high complexity, with 
a large number of tributaries all along its course (Figure 1c). The main channel is highly fragmented, with 37 identified weirs $(<3 \mathrm{~m}$ high) as well as two dams ( $30 \mathrm{~m}$ high), respectively, located 30 and $80 \mathrm{~km}$ from the source. Finally, $60 \%$ of the Viaur drainage basin is covered by agricultural areas.

We focused on two widely distributed species in Southwestern France: the Languedoc gudgeon G. occitaniae and the Eurasian minnow P. phoxinus. Both species are of similar maximal body length (200 and $140 \mathrm{~mm}$, respectively), belong to the same family (Cyprinidae) and to the same trophic level: they are insectivorous, although G. occitaniae preferentially feeds on the bottom, whereas $P$. phoxinus feeds in the water column. They are both abundant species with supposedly large effective population size, which suggests that the effect of genetic drift might be similar between species. However, P. phoxinus is less tolerant than G. occitaniae, which leads to a narrower spatial distribution and potentially to a higher (genetic) sensitivity to stressors such as habitat degradation.

\section{2 | Genetic sampling and genotyping}

In 2010, 22 and 25 sites were, respectively, sampled along the main channels of the Célé and Viaur Rivers (Figure 1), with up to 30 adults from each species caught by electrofishing (Table S2). For each individual, we collected and preserved in $70 \%$ ethanol a small piece of pelvic fin. All individuals were released alive in their respective sampling site. Fieldwork was conducted in accordance with French laws and with adequate administrative permits for electrofishing.

Genomic DNA was extracted using a salt-extraction protocol (Aljanabi \& Martinez, 1997). A subset of 11 and 16 autosomal microsatellite loci chosen among those described in Grenier, Costedoat, Chappaz, and Dubut (2013; Table S1) were amplified and genotyped in $G$. occitaniae and $P$. phoxinus, respectively. Polymerase chain reactions (PCR) and genotyping were performed as detailed in Grenier et al. (2013). The presence of null alleles was assessed at each locus by analysing homozygote excess in each population using MICROCHECKER 2.2.3 (Van Oosterhout, Hutchinson, Wills, \& Shipley, 2004). We also checked for gametic disequilibrium using GENEPOP 4.2.1 (Rousset, 2008) after sequential Bonferroni correction to account for multiple related tests (Rice, 1989). We discarded from further analyses any locus showing significant gametic disequilibrium and/or evidence of null alleles, resulting in the withdrawal of three loci in $P$. phoxinus, for a total number of 13 loci in this species Genetic characteristics of sampled populations are given in Table S2.

\section{3 | Measures of genetic diversity and genetic differentiation}

For each dataset (gudgeons in the Célé River, gudgeons in the Viaur River, minnows in the Célé River and minnows in the Viaur River), we computed three genetic metrics. The two-first metrics stood for local genetic diversity: the standardised $A R$ and the standardised private allelic richness (PA). Both AR and PA were computed using the rarefaction procedure implemented in ADZE 1.0 (Szpiech, Jakobsson, \& Rosenberg, 2008), with 20 as the standardised sample size across all populations (i.e., the lowest number of individuals caught at the site level, except for site 22 on the river Viaur where only 12 minnows were caught; see Table S2). The third metric stood for local genetic uniqueness UNI and was computed as the average of pairwise G'st values observed between a deme and all other demes (Coleman, Weeks, \& Hoffmann, 2013; Hedrick, 2005). G'st values, allowing comparison of estimates among species, were computed using the R package diveRsity (Keenan, McGinnity, Cross, Crozier, \& Prodöhl, 2013).

\section{4 | Localisation of stocking}

Local angling associations reported that both studied rivers have been stocked with non-native gudgeons Gobio gobio (Linnaeus, 1758) and/or non-native minnows from the Loire River basin (France). Stocking occurred a few times in the few years preceding the sampling session. For each species, we used the Bayesian clustering algorithm implemented in STRUCTURE (Pritchard, Stephens, \& Donnelly, 2000) with non-native genotypes from the Arroux River (Loire River basin; 90 individuals for each species, from three distinct locations; see Figure S1) as an outlier group to identify stretches in which these stocking events occurred (Zalapa, Brunet, \& Guries, 2010).

\subsection{Environmental predictors}

We considered 18 variables that were likely to affect local genetic diversity and uniqueness. These variables were classified into four main categories, depending on whether they were related to natural characteristics of the rivers, anthropogenic fragmentation of the main channel, land use in the vicinity of each site or local probability of an influence of stocking.

For variables related to natural characteristics of the rivers, we considered the sites' river distance from the source, the local altitude, the Strahler stream order class, the number and the cumulated length of all upstream tributaries, the river width, the mean temperature (in situ measurements during summer 2015 using a Hobo Pendant Temperature data logger) and the concentration in dissolved oxygen, as well as the betweenness centrality index of each site within the network that measures how often a node serves as a bridge between upstream and downstream nodes along a network (ComplexNetGIS toolbox in ARCGIS; Caschili, 2010). Although possibly affected by various anthropogenic effects, river width, temperature and concentration in dissolved oxygen are usually highly correlated with distance from the source and were thus here considered as natural variables (Table 1) rather than estimates of habitat degradation. For anthropogenic fragmentation, we considered the number of weirs, the number of dams and the cumulated height of obstacles (including both weirs and dams) in a $2-\mathrm{km}$ buffer around each sampling site, so as to take into account both upstream and 
TABLE 1 Contribution of raw variables to principal components (Axis 1 and Axis 2) in each river (CELE, VIAUR). Principal component analyses were performed on variables classified into four thematic categories. For each river, the table provides the coordinates of raw variables on the two-first axes, the total inertia of each axis, as well as its interpretation. In bold, coordinates of variables with a substantial contribution to the axis. In italic: discarded axes. UDG, upstream-downstream gradient; BET, betweenness; CRO, crops; URB, urban areas; HR, home range; LI, low inertia (<10\%); NR, non-representative axis; RI, axis with a redundant interpretation

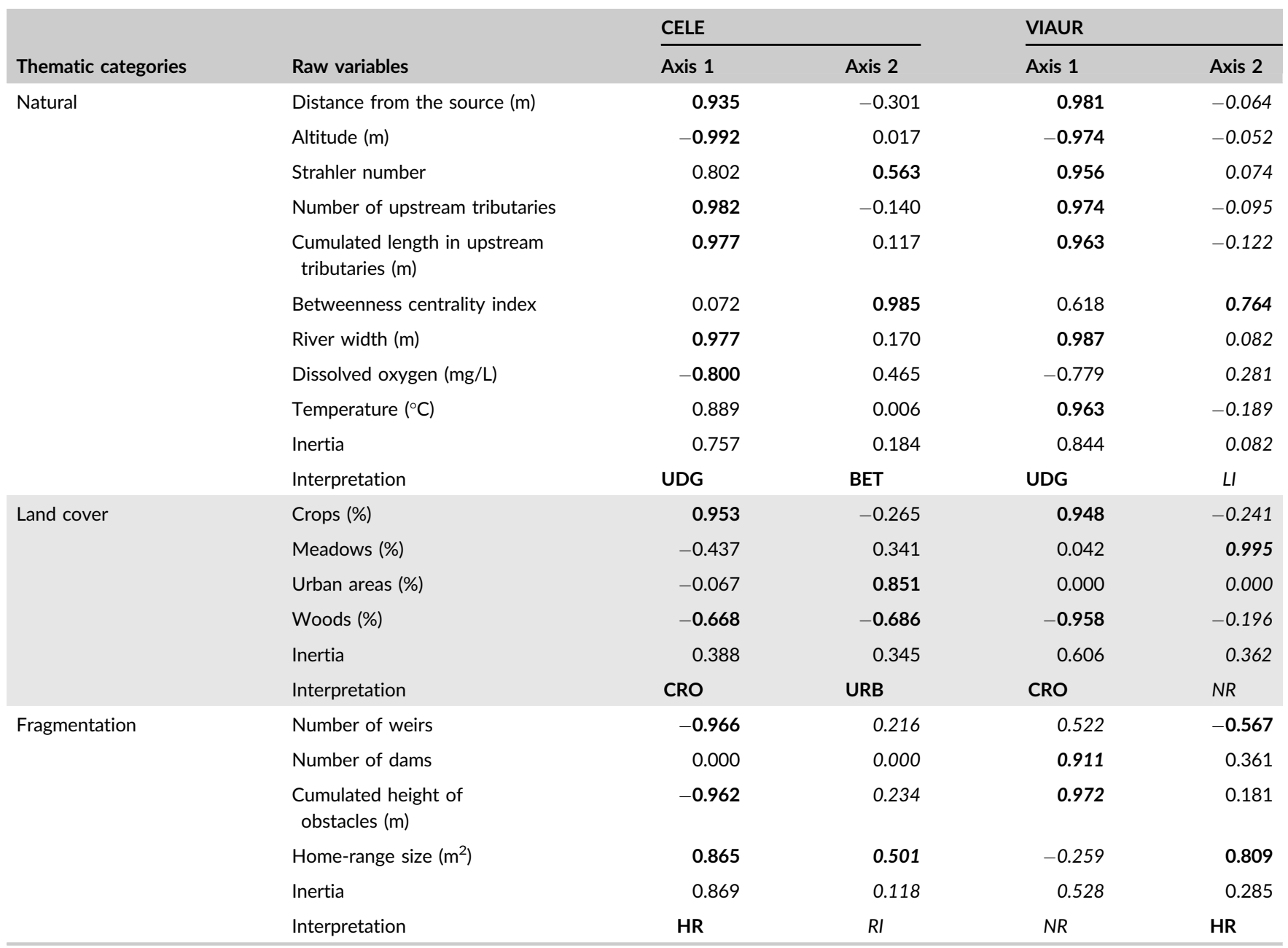

downstream possible reduction in dispersal movements. We also considered estimates of home-range sizes, calculated as the surface of free water (length $\times$ width of both the main channel and tributaries) delimited by upstream and downstream first obstacles (weirs

TABLE 2 Thematic predictors considered in each dataset

\begin{tabular}{llllll} 
& \multicolumn{1}{l}{ Célé } & & Viaur & \\
\cline { 2 - 3 } \cline { 5 - 6 } Predictors & $\begin{array}{l}\text { Gobio } \\
\text { occitaniae }\end{array}$ & $\begin{array}{l}\text { Phoxinus } \\
\text { phoxinus }\end{array}$ & & $\begin{array}{l}\text { Gobio } \\
\text { occitaniae }\end{array}$ & $\begin{array}{l}\text { Phoxinus } \\
\text { phoxinus }\end{array}$ \\
UDG & $\times$ & $\times$ & $\times$ & $\times$ \\
UDG2 & $\times$ & $\times$ & $\times$ & $\times$ \\
BET & $\times$ & $\times$ & & \\
CRO & $\times$ & $\times$ & $\times$ & $\times$ \\
URB & $\times$ & $\times$ & & $\times$ \\
HR & $\times$ & $\times$ & $\times$ & $\times$ \\
\hline STO & $\times$ & & $\times$ & \\
\hline
\end{tabular}

or dams; Prunier, Dubut, et al., 2017). Local levels of habitat degradation were represented using estimates of local land use, computed from the Corine LandCover 2006 dataset (European Environment Agency) as the respective percentage of urban areas, woods, meadows and cultivated crops in a 2-km buffer around each sampling site. Land cover in the vicinity of rivers being known to drastically impact stream's ecological integrity (local inputs of pollutants, impacts on riparian and stream channel habitat, flow alteration, etc.), it constitutes an integrative proxy for both water quality and microhabitat quality (Allan, 2004). Finally, when applicable (see "Section 2.4"), we estimated the probability $p$ of each site being impacted by recent stocking events according to the following equation:

$$
p=\left(1-\frac{d}{d \max }\right) \times \frac{1}{\alpha}
$$

with $d$ the distance between each deme and the closest upstream or downstream stocking site, $d_{\max }$ the maximal recorded distance between a sampling site and a stocking site, and $\alpha$ an asymmetry 
coefficient taking into account reduced upstream migration rates in each species ( $\alpha=1$, except for sites located upstream of the most upstream stocking event where $\alpha=6.437$ (Gudgeons from the Célé River), 9.08 (Gudgeons from the Viaur River) and 8.631 (Minnows from the Viaur River), as estimated by Paz-Vinas, Quéméré, Chikhi, Loot, \& Blanchet, 2013). This probability ranged from 0 (minimal impact of stocking) to 1 (maximal impact).

\subsection{Data manipulation and statistical analyses}

Box 1 illustrates as a flowchart the three major steps of the analytical framework we used to handle these data and cope with multicollinearity issues.

\subsection{1 | Step 1-creation of thematic predictors}

All variables belonging to the same category (except for stocking probability) were compiled using principal components analyses ( $R$ function dudi.pca; package ade4). The contribution of each raw variable to an axis was considered as substantial when it was higher than the value expected under the assumption of a uniform contribution of the variable ( $R$ function fviz_contrib; package factoextra). The two-first principal components were systematically retained, except when the amount of variance explained by one of the component did not exceed 10\% (axis with little inertia), when the cumulated absolute contribution of the two most influential points to the axis ( $R$ function inertia.dudi; package ade4) exceeded 50\% (nonrepresentative axis) or when the biological interpretation of the second component was redundant with the interpretation of the first one (redundant interpretation), in which case the corresponding axis was discarded (Table 1). To limit multicollinearity issues (Dormann et al., 2013; Prunier, Colyn, Legendre, Nimon, \& Flamand, 2015), we also checked that pairs of predictors showed univariate Pearson's correlation coefficients lower $|r|=.8$. Individual coordinates on each of the retained principal components were used to create thematic predictors in the following statistical analyses. This procedure resulted in six possible thematic predictors (UDG, BET, CRO, URB, HR and STO), each one representing a possible driver of genetic variability (Tables 1 and 2): UDG stood for the upstream-downstream gradient in natural characteristics of rivers (e.g., distance from the source, altitude, temperature); BET stood for an increase in the betweenness centrality index; CRO and URB, respectively, stood for an increase in crops and in urban areas in a 2-km buffer around each site; HR stood for an increase in the home range; finally, STO was kept unchanged and stood for the probability of being impacted by recent stocking events.

\subsection{2 | Step 2-model selection and regression commonality analyses}

For each dependent variable (AR, PA and UNI) and each dataset, we designed a complete linear model including all retained thematic predictors along with all possible first-order interactions. Additive (simple) regression coefficients can be interpreted as the effect of a predictor when all other predictors are set to zero (Aiken, West, \& Reno, 1991; Appendix S1). As they stemmed from principal components, all predictors but STO were centred: all additive terms could thus be interpreted as the effect of a predictor in absence of stocking $(\mathrm{STO}=0)$ and for intermediate values of other predictors $($ mean $=0)$. We also included the squared predictor UDG, hereafter named UDG2, as quadratic relationships between genetic diversity and distance from the source may arise from dendritic branching patterns (Paz-Vinas \& Blanchet, 2015). Given the limited size of each dataset, we simplified these complete models by discarding any additive or interaction term showing a univariate squared correlation $r^{2}$ with the dependent variable lower than .1, except for additive terms involved in retained interactions. The rationale for this withdrawal is that predictors showing no or little correlation with the dependent variable are likely to act as statistical suppressors, leading to a possible distortion of regression coefficients, as well as a distortion of their standard errors and marginal statistics used to test their significance (Paulhus, Robins, Trzesniewski, \& Tracy, 2004; Prunier, Colyn, Legendre, \& Flamand, 2017; Prunier et al., 2015). Suppressors are of three kinds (Conger, 1974): classical, reciprocal and cross-over suppressors. In classical and reciprocal suppression situations, a suppressor variable, although unrelated (or only slightly related) to the dependent variable, receives a high standardised regression weight when it is included in the model. In cross-over suppression, a suppressor shows a slight (positive or negative) relationship with the dependent variable but is yet assigned a large standardised regression weight, with an opposite sign when compared with its univariate correlation with the dependent variable. Discarding predictors with low univariate squared correlation thus led to the design of a reduced model for each dataset, only containing additive and interaction terms likely to explain non-negligible amounts of variance in the dependent variable. We then performed automated model selection based on Akaike's information criterion (AICC) as a measure of model fit (Burnham \& Anderson, 2002), with a maximum of seven terms at a time in a tested model to avoid overfitting (function dredge in Rpackage MuMIn; Barton, 2016). Given the imbalance in the number of models containing each variable (Burnham \& Anderson, 2002), we did not investigate the relative importance of each variable but solely focused on the analysis of the most parsimonious model $(\triangle \mathrm{AICc}=0)$. Nevertheless, we considered the number of occurrences of each predictor within the best set of models $(\triangle \mathrm{AICc}<4)$ as an indication of relative support for each variable.

Some suppressors were likely to be retained in the course of AIC-based model selection as the inherent characteristic of suppressors is to artefactually increase model fit (Ray-Mukherjee et al., 2014). We thus used commonality analyses (CA; Nimon, Lewis, Kane, \& Haynes, 2008; Prunier et al., 2015; Ray-Mukherjee et al., 2014) to identify - from the best selected model for each dependent variable - the main contributors to the variance in the dependent variable while revealing spurious correlations stemming from synergistic associations among collinear predictors or from suppression 
situations (Prunier et al., 2015). For each best model, we used CA ( $R$ package yhat; Nimon, Oswald, \& Roberts, 2013) to identify and discard possible suppressors and unnecessary predictors (as long as they were not involved in interaction terms; see Table S3). Variables were identified as suppressors when their unique contribution was (almost) totally counterbalanced by a negative commonality coefficient (classical and reciprocal suppression) or when standardised regression coefficients and univariate correlation coefficients were of opposite signs (cross-over suppression; Prunier, Colyn, et al., 2017). Variables were identified as unnecessary when their unique contribution $(U)$ was substantially low $(U<1 \%)$ and lower than their common contribution, indicating that they only contributed to the variance in the dependent variable because of their synergistic association with another predictor (Prunier et al., 2015). The purpose of this framework was to avoid some predictors to influence the estimates of other important effects in subsequent analyses.

To quantify the relative contribution of natural features (UDG, UDG2 and BET) and anthropogenic stressors (HR, CRO, URB, STO and interactions involving anthropogenic stressors) to genetic variability, we computed averaged unique contributions of all possible predictors per species, rivers, genetic metrics and across all datasets. Predictors absent from a given model were given a unique contribution of 0 . Results were plotted into $100 \%$ stacked barplots.

\subsection{3 | Step 3-meta-analysis}

We finally used a meta-analytic framework to investigate the magnitude (effect sizes) and precision (95\% confidence intervals) of the effects of each thematic predictor on AR, PA and UNI across species and rivers. For each predictor and each dataset, we first calculated the $r$ statistic, a standardised effect statistic for continuous variables that belongs to the family of correlation coefficients (Nakagawa \& Cuthill, 2007). $r$ statistics were computed as follows:

$$
r=\frac{t}{\sqrt{t^{2}+d f}}
$$

with $t$ values and $d f$ values (the number of degrees of freedom) obtained from the final multiple regression models (Nakagawa \& Cuthill, 2007, eq. 11). We converted $r$ statistics to Fisher's $z$ metrics using the Fisher's $z$ transformation as follows (Nakagawa \& Cuthill, 2007, eq. 20):

$$
z=0.5 \times \ln \left(\frac{1+r}{1-r}\right)
$$

Contrary to $r$ statistics, Fisher's $z$ metrics are normally distributed. We then computed the variance $v_{z}$ and the standard error $s e_{z}$ of each Fisher's z metric as follows (Nakagawa \& Cuthill, 2007, eq. 19):

$$
v_{z}=\frac{1}{n-3} \text { and } s e_{z}=\sqrt{v_{z}}
$$

with $n$ the sample size of each dataset.

In order to obtain the most precise estimate (or summary effect) of each predictor across datasets, we calculated $M$, the weighted mean of Fisher's $z$ metrics, with the weight $W_{i}$ assigned to each dataset $i$ being the inverse of within-dataset variance $v_{z i}$ (Borenstein, 2009, eqs. 11.2-11.3):

$$
W_{i}=\frac{1}{v_{z i}} \text { and } M=\frac{\sum_{i=1}^{k} W_{i} z_{i}}{\sum_{i=1}^{k} W_{i}}
$$

Finally, 95\% lower and upper limits for summary effects $M$ were computed as (Borenstein, 2009, eqs. 11.5-11.7):

$$
M \pm 1.96 \times \sqrt{V_{M}}
$$

with $V_{M}$ the variance of the summary effect $M$, estimated as the reciprocal of the sum of the weights $W_{i}$ across datasets (Borenstein, 2009, eq. 11.4):

$$
V_{M}=\frac{1}{\sum_{i=1}^{k} W_{i}}
$$

All statistical analyses were performed in R 3.1.2 ( $R$ Development Core Team 2014).

\section{3 | RESULTS}

Three stocking places were reported by local angling associations: two in the Célé River with non-native gudgeons released in sites 12 and 22 (Figure 1b), and one in the Viaur River with both non-native gudgeons and minnows released in site 22 (Figure 1c; see also Figure S1). The Bayesian clustering procedure pointed out both pure non-native G. gobio and G. occitaniae $\times$ G. gobio hybrids in sites 12 , 13 and 22 in the Célé River (Figure S1). Although minnows from the Viaur River did not show introgression with respect to the STRUCTURE analysis (Figure S1), a discriminant analysis of principal components (dAPC; Jombart, Devillard, \& Balloux, 2010) pointed the site 22 as an outlier (Figure S2), corroborating reports by local angling associations.

From 3 to 15 models were identified as part of the best sets of models $(\triangle \mathrm{AIC}<<4)$ across datasets (Table 3 ). The relative support of predictors ranged from 0.33 to 1 . After withdrawal of suppressors and unnecessary variables, best fitting models $(\triangle \mathrm{AIC} c=0)$ comprised from 1 to 5 predictors.

Considering AR, adjusted multiple $R^{2}$ ranged from 0.629 to 0.950 , indicating that retained predictors correctly captured most of genetic variability in all datasets (Table 3 ). None of the predictors related to land cover (CRO, URB) were retained as possible drivers of $A R$. Whatever the dataset, $A R$ increased along the upstream-downstream gradient (UDG; Figure 2). We also identified quadratic relationships between AR and UDG in gudgeons from the Célé River and minnows from the Viaur River, the former concave (bell-shaped) and the latter convex (U-shaped; Figure 3). The increase in both local connectivity (BET) and local home range were further found to covary positively with $A R$, in minnows from the Céle River and in gudgeons from the Viaur River, respectively (Table 3). Finally, AR in gudgeons from both rivers increased with stocking probability STO (Figure 2).

For the PA, adjusted multiple $R^{2}$ ranged from 0.279 to 0.671 (Table 3). The only retained predictors were UDG (in minnows) and STO (in gudgeons; Figure 2). PA increased along UDG in minnows from both rivers, with a $U$-shaped quadratic relationship in minnows 
TABLE 3 For each river and each species (Sp), results of multiple linear regressions, as well as additional parameters derived from CA: dependent variables (DV), adjusted coefficient of determination (adj. $R^{2}$ ), predictors (Pred), regression coefficients (Coef), $p$-values corrected for false discovery rate (Pval), and unique, common and total contributions of predictors to the variance in the dependent variable $(U, C$ and $T)$. RS: relative support of each predictor, defined here as the ratio of the number of occurrences of each predictor within the best set of models over the number of best models ( $\triangle \mathrm{AIC}<4$ ). In bold: Significant $p$-values at $\alpha=5 \%$

\begin{tabular}{|c|c|c|c|c|c|c|c|c|c|c|}
\hline DV & River & Sp & Adj. $R^{2}$ & Pred & RS & Coef & Pval & $U$ & $C$ & $T$ \\
\hline \multirow[t]{9}{*}{$A R$} & \multirow[t]{5}{*}{ Célé } & \multirow[t]{3}{*}{ G } & \multirow[t]{3}{*}{0.679} & Intercept & - & 6.141 & 0.000 & - & - & - \\
\hline & & & & UDG & $11 / 11$ & 0.060 & 0.076 & 0.071 & 0.407 & 0.478 \\
\hline & & & & STO & $5 / 11$ & 0.361 & 0.076 & 0.054 & 0.360 & 0.414 \\
\hline & & \multirow[t]{2}{*}{$M$} & \multirow[t]{2}{*}{0.950} & Intercept & - & 6.322 & 0.000 & - & - & - \\
\hline & & & & BET & $6 / 6$ & 0.275 & 0.000 & 0.144 & 0.000 & 0.144 \\
\hline & \multirow[t]{4}{*}{ Viaur } & \multirow[t]{4}{*}{ G } & \multirow[t]{4}{*}{0.629} & Intercept & - & 4.912 & 0.000 & - & - & - \\
\hline & & & & UDG & $12 / 15$ & 0.068 & 0.054 & 0.065 & 0.385 & 0.449 \\
\hline & & & & $\mathrm{HR}$ & $14 / 15$ & 0.181 & 0.041 & 0.121 & 0.103 & 0.224 \\
\hline & & & & STO & $11 / 15$ & 0.702 & 0.041 & 0.093 & 0.379 & 0.471 \\
\hline \multirow[t]{9}{*}{ PA } & \multirow[t]{4}{*}{ Célé } & \multirow[t]{2}{*}{ G } & \multirow[t]{2}{*}{0.403} & Intercept & - & 0.077 & 0.000 & - & - & - \\
\hline & & & & STO & $11 / 13$ & 0.127 & 0.001 & - & - & 0.431 \\
\hline & & \multirow[t]{2}{*}{$M$} & \multirow[t]{2}{*}{0.666} & Intercept & - & 0.236 & 0.000 & - & - & - \\
\hline & & & & UDG & $10 / 10$ & 0.028 & 0.004 & - & - & 0.682 \\
\hline & \multirow[t]{5}{*}{ Viaur } & \multirow[t]{2}{*}{$\mathrm{G}$} & \multirow[t]{2}{*}{0.279} & Intercept & - & 0.119 & 0.000 & - & - & - \\
\hline & & & & STO & $6 / 10$ & 0.098 & 0.031 & - & - & 0.309 \\
\hline & & \multirow[t]{3}{*}{ M } & \multirow[t]{3}{*}{0.671} & Intercept & - & 0.093 & 0.000 & - & - & - \\
\hline & & & & UDG & $4 / 4$ & 0.016 & 0.000 & 0.325 & -0.062 & 0.263 \\
\hline & & & & UDG2 & $4 / 4$ & 0.007 & 0.000 & 0.435 & -0.062 & 0.373 \\
\hline & & & & HR:STO & $3 / 3$ & -0.037 & 0.000 & 0.446 & -0.145 & 0.301 \\
\hline & & $M$ & 0.901 & Intercept & - & 0.049 & 0.000 & - & - & - \\
\hline & & & & UDG & $7 / 7$ & -0.005 & 0.000 & 0.205 & 0.276 & 0.482 \\
\hline & & & & BET & $7 / 7$ & -0.010 & 0.000 & 0.323 & 0.023 & 0.346 \\
\hline & & & & URB & $5 / 7$ & 0.000 & 0.821 & 0.000 & 0.080 & 0.080 \\
\hline & & & & URB:UDG & $5 / 7$ & 0.003 & 0.004 & 0.071 & 0.254 & 0.325 \\
\hline & Viaur & G & 0.565 & Intercept & - & 0.015 & 0.000 & - & - & - \\
\hline & & & & $\mathrm{HR}$ & $4 / 4$ & -0.002 & 0.185 & 0.039 & -0.014 & 0.025 \\
\hline & & & & STO & $4 / 4$ & 0.010 & 0.062 & 0.092 & 0.222 & 0.314 \\
\hline & & & & HR:STO & $4 / 4$ & 0.020 & 0.004 & 0.246 & 0.177 & 0.423 \\
\hline & & $M$ & 0.824 & Intercept & - & 0.027 & 0.000 & - & - & - \\
\hline & & & & UDG & $3 / 3$ & -0.002 & 0.067 & 0.031 & 0.038 & 0.070 \\
\hline & & & & UDG2 & $3 / 3$ & 0.001 & 0.008 & 0.079 & 0.366 & 0.446 \\
\hline & & & & STO & $3 / 3$ & 0.058 & 0.000 & 0.273 & 0.349 & 0.622 \\
\hline
\end{tabular}




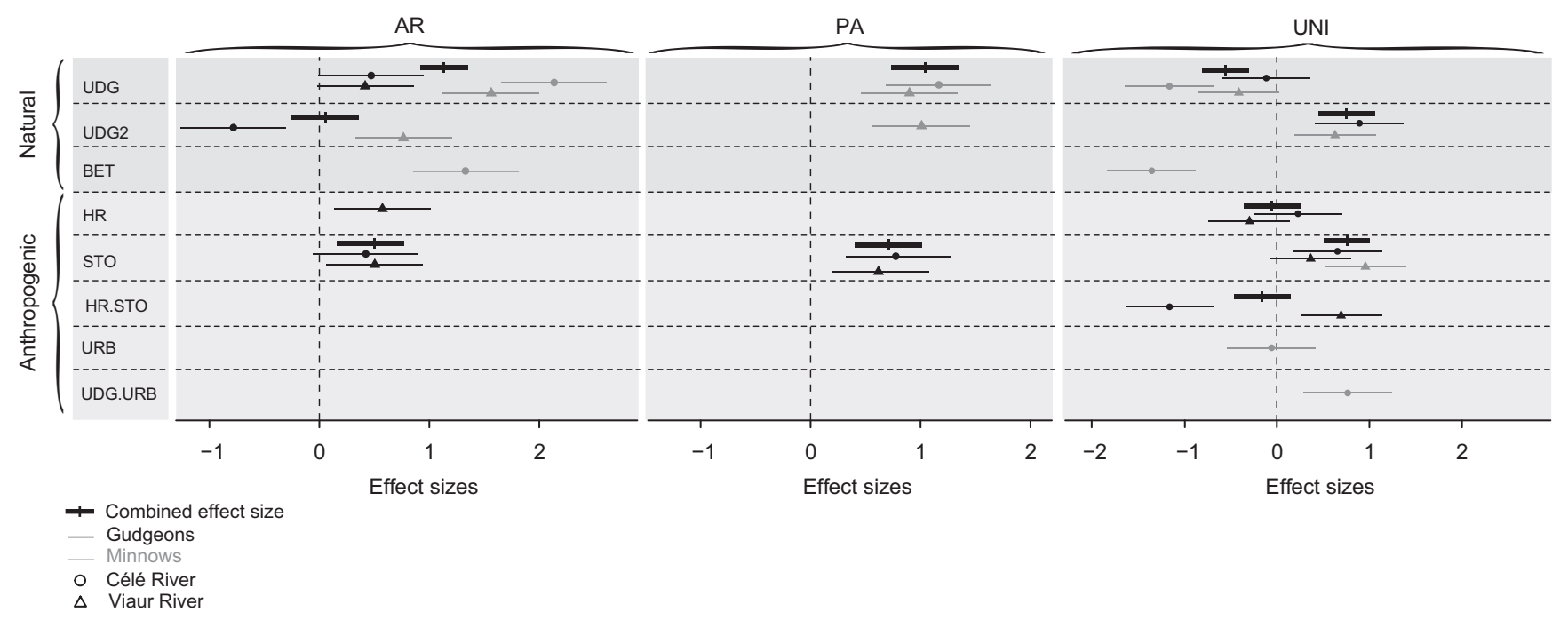

FIGURE 2 Effect sizes (and 95\% confidence intervals) of all retained predictors for allelic richness (AR), private allelic richness (PA) and uniqueness (UNI), as computed from the meta-analysis framework

from the Viaur River (Figure 3). PA increased with stocking probability in gudgeons from both rivers.

Results regarding genetic uniqueness (UNI) were more variable across datasets, with some interactions between predictors. Adjusted multiple $R^{2}$ ranged from 0.565 to 0.901 (Table 3). UNI decreased along UDG in minnows from both rivers, with a $U$-shaped quadratic relationship in minnows from the Viaur River (Figures 2 and 3). We also found a U-shaped quadratic relationship between UNI and UDG in gudgeons from the Célé River, but without any significant downstream decrease of UNI. Local connectivity (BET) was associated with a decrease in UNI only in minnows from the Célé River (Figure 2). In all datasets with stocking events, we found a positive correlation between UNI and STO (Figure 2). Nevertheless, we identified contrasting interactions of stocking with home range (HR) in gudgeons (Figure 4a,b): in absence of stocking, UNI did not significantly covary with HR, but showed a significant decrease in the Célé River, as opposed to a significant increase in the Viaur River, as stocking probability increased. A last interaction was retained between urban areas (URB) and UDG in minnows from the Célé River: the negative relationship between UNI and UDG identified for low to intermediate values of URB was reversed as URB increased (Figure 4c).

Overall, only predictors UDG and STO showed congruent effect sizes across datasets, with UDG positively correlated with AR and PA and negatively correlated with UNI, and STO positively correlated with all dependent variables (Figure 2). Other predictors were either retained in single datasets (e.g., BET) or showed opposite relationships across datasets (e.g., HR.STO). As a result, the relative contributions of natural features and anthropogenic stressors varied largely between species (Figure 5a), with genetic variability being mostly explained by anthropogenic stressors (STO; 77\%) in gudgeons and by natural features (UDG; 96\%) in minnows $\left(\chi^{2}=107.6\right.$; $p<.000$ ). Although slightly higher, the relative contribution of anthropogenic stressors on genetic variability across species in the Viaur River (42\%) was not significantly different from the one in the
Célé River (32\%; $\chi^{2}=1.7 ; p=.18$; Figure 5a). Pooling all datasets, the relative contributions of natural features to the variance of $A R$ and PA were, respectively, more than five times and almost twice higher than the contribution of anthropogenic stressors (Figure 5b). On the contrary, the contribution of anthropogenic stressors to the variance in $\mathrm{UNI}$ was higher than the contribution of natural features. Overall, the here tested natural features contributed 1.82 times more than anthropogenic stressors to genetic variability.

\section{DISCUSSION}

\subsection{Contribution of the natural river network structure}

Natural features such as upstream-downstream gradients, dendritic branching patterns and local connectivity in confluence zones are known as important drivers of genetic variability in dendritic river networks, as they directly influence patterns of gene flow and genetic drift. Several studies highlighted general and repeatable patterns in their effects (Paz-Vinas \& Blanchet, 2015; Paz-Vinas et al., 2015; Thomaz et al., 2016). One of these patterns is the DIGD (PazVinas et al., 2015) which involves a downstream increase in AR. In fish, DIGD is assumed to result from different, possibly interacting mechanisms such as local historical context (e.g., upstream-directed colonisation, with successive founder effects leading to an upstream impoverishment in alleles) and river structure (e.g., downstream increase in effective population sizes through increased habitat availability; Paz-Vinas et al., 2015). In line with these theoretical expectations, our meta-analysis revealed that upstream-downstream gradients were strong and consistent drivers of genetic variability across species and rivers: both $A R$ and PA increased along the upstream-downstream gradients, with significant effect sizes across datasets (see also Figure S2). We also found a consistent decrease in genetic uniqueness along the upstream-downstream gradients in 

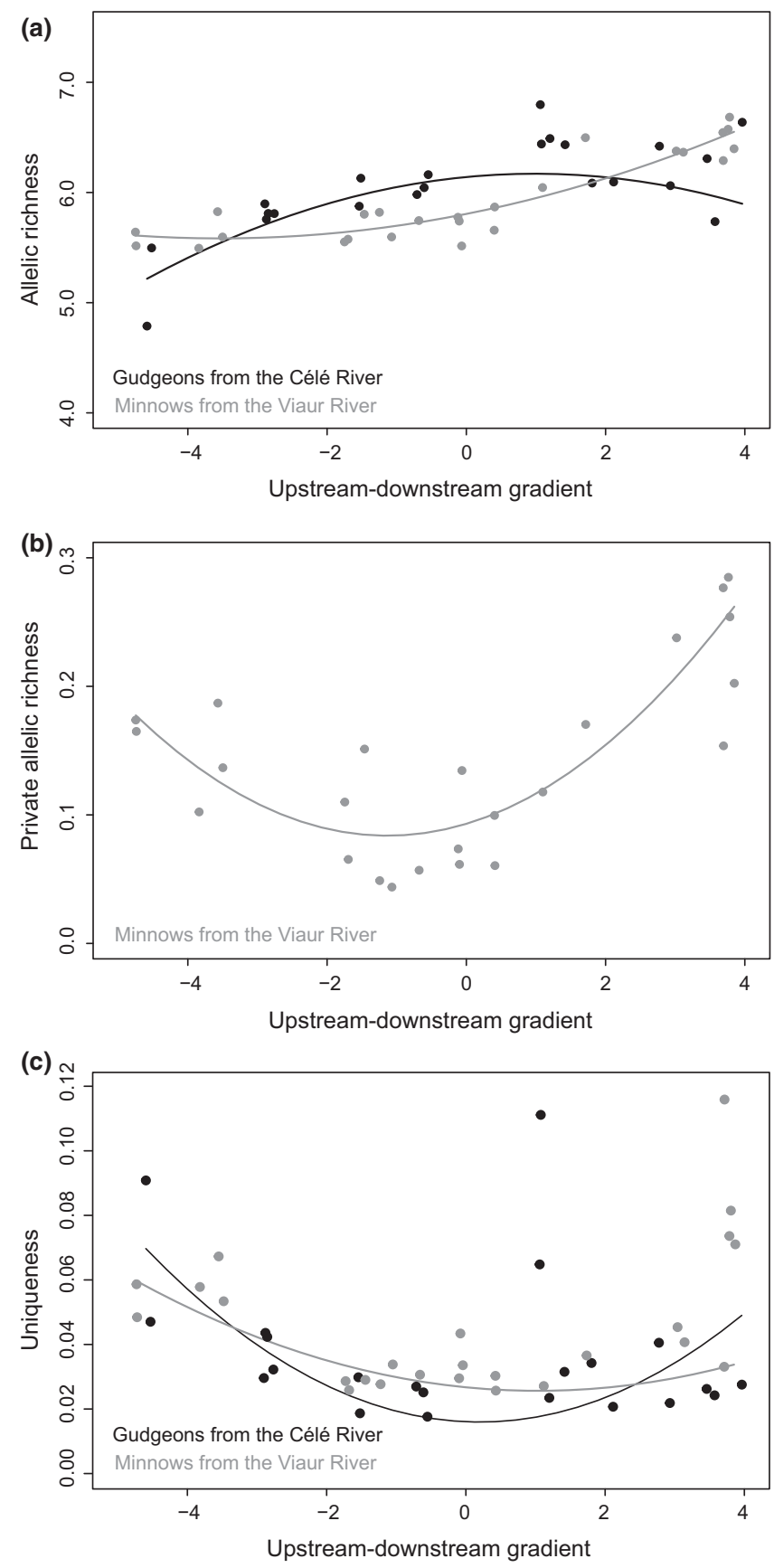

FIGURE 3 When predictor UDG2 was retained in final models, convex and concave bell-shape relationships of AR (a), PA (b) and UNI (c) along the upstream-downstream gradient in gudgeons from the Célé River (in black) and minnows from the Viaur River (in grey). Dots stand for raw data

minnows. Such a downstream decrease in genetic differentiation was already observed in several studies (e.g., Finn, Bonada, Múrria, \& Hughes, 2011), and it was shown to primarily result from dendritic connectivity, possibly reinforced in combination with asymmetric gene flow, differences in population sizes and upstream-directed colonisation (Paz-Vinas et al., 2015). These relationships were not always linear, as we found both bell-shaped and U-shaped relationships between genetic metrics and upstream-downstream gradients (a)

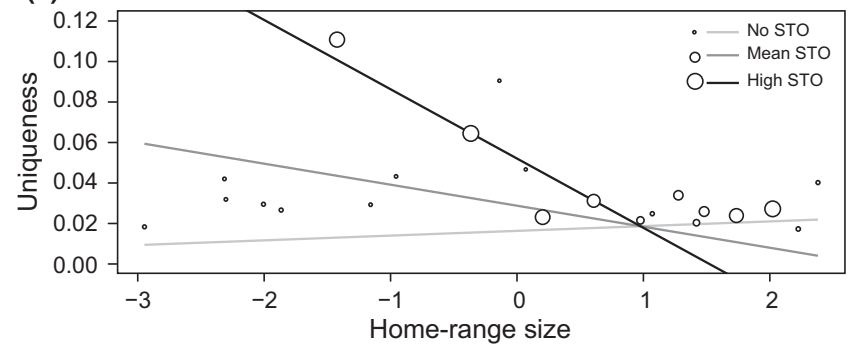

(b)

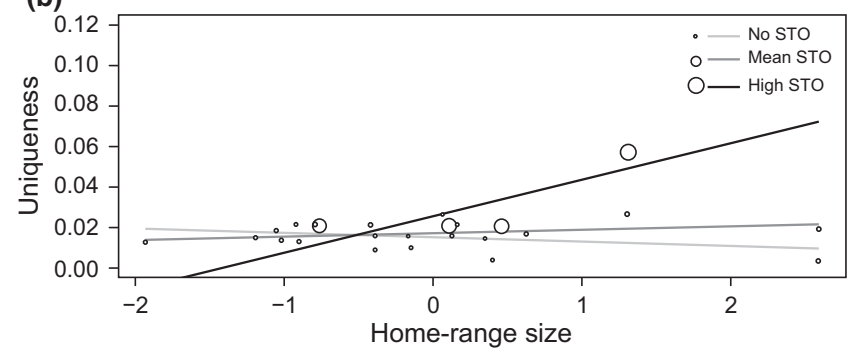

(c)

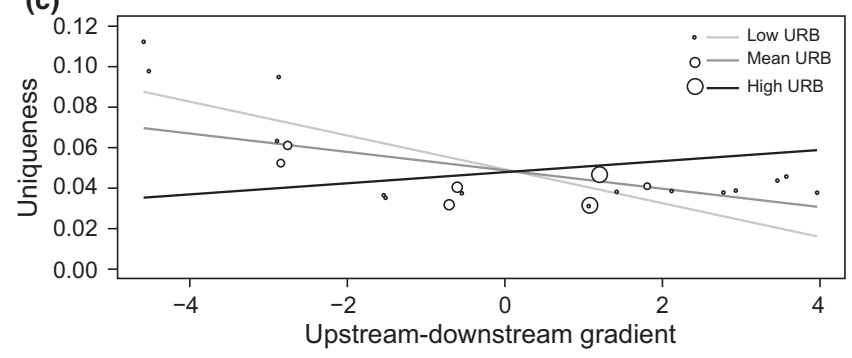

FIGURE 4 Uniqueness was partly explained by interactions between STO and HR in gudgeons from the Célé River (a) and in gudgeons from the Viaur River (b), and between UDG and URB in minnows from the Célé River (c). Circles represent the second term of the interactions (STO in panels a and b; URB in panel c) with size of circles proportional to the values

in two datasets (quadratic term UDG2 retained in final models). Such nonlinear relationships, reported in both empirical and simulation studies (Paz-Vinas \& Blanchet, 2015; Paz-Vinas et al., 2015), may arise from the allelic enrichment of populations benefiting from dispersal from tributaries (branching pattern), but also from other peculiarities of studied systems such as historical contingencies. The bell-shaped relationship in gudgeons from the Célé River probably stemmed from the influence of tributaries on AR in demes located at intermediate distances from the river source. The specific topology of the Céle River, with a large amount of branching in the upstream half part of the main channel but a very simple topology in its downstream part, was indeed very similar to simplified dendritic networks used in the simulation study by Paz-Vinas and Blanchet (2015), who provided the first theoretical evidence of bell-shaped relationships arising from dendritic branching patterns in species with low to intermediate migration rates. Conversely, U-shaped relationships observed in minnows from the Viaur River could stem from an increase in habitat quality in upstream demes (Keith, Persat, Feunteun, Adam, \& Geniez, 2011) and from an enrichment of downstream genetic pools by dispersal individuals coming from unsampled demes in the main stem or in tributaries located downstream. 


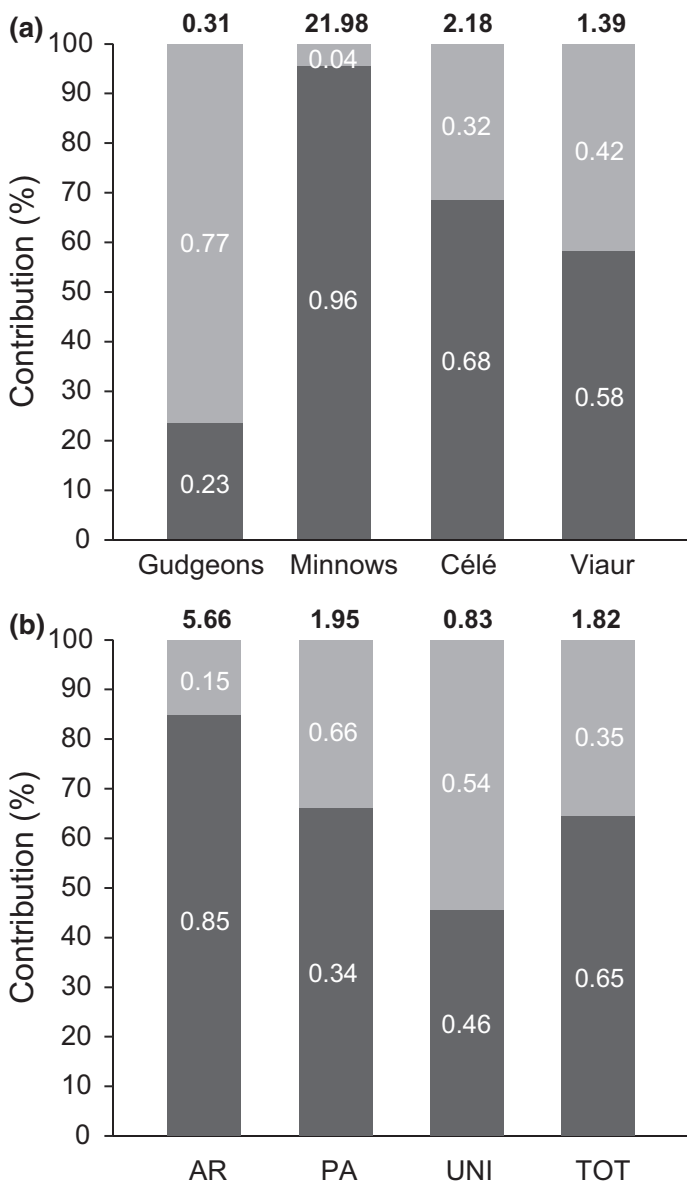

FIGURE 5 Averaged relative contributions of natural features (UDG, UDG2 and BET; in dark grey) and anthropogenic stressors (HR, CRO, URB, STO and interactions involving anthropogenic features) to (a) genetic characteristics in each species and each river system and to (b) each dependent variable (AR, PA, UNI) and combined variables (TOT) across datasets. Numbers in black represent the ratio of contributions of natural features over anthropogenic features

While the possible large-scale influence of dendritic connectivity was taken into account with quadratic terms UDG2, local betweenness was identified as another natural predictor favouring an increase in $A R$ and a decrease in uniqueness for minnows living in highly connected demes from the Célé River. Although not retained in final models, we found similar trends in gudgeons from the Célé River (data not shown). As central nodes within the network, these highly connected demes may receive alleles from unsampled populations from tributaries but also from the main channel through downstream-orientated gene flow (Morrissey \& de Kerckhove, 2009), thus increasing local AR but also limiting genetic uniqueness when compared with more isolated demes.

\subsection{Contribution of anthropogenic stressors}

Possibly interacting with natural characteristics of river systems, human activities are known to critically affect evolutionary processes such as gene flow and genetic drift through riverscape fragmentation, habitat degradation or stocking (Hoffmann \& Willi, 2008). Among the various anthropogenic stressors considered in this study, only stocking had a strong and consistent influence on patterns of genetic diversity and genetic differentiation, notably in gudgeons. Stocking of small game fish species such as minnows and gudgeons in freshwater rivers is a common practice that notably aims at sustaining angling activities (Arlinghaus, Beardmore, Riepe, Meyerhoff, \& Pagel, 2014). However, introduced fish usually originate from hatcheries or other geographical regions and bear original genetic signatures, with different impacts on autochthonous genetic pools depending on the intensity of stocking practices (Marie et al., 2010). We expected moderately stocked populations to experience an increase in both $A R$ and PA but also an increase in genetic uniqueness through local introgression of non-native alleles (Marie et al., 2010; Perrier, Guyomard, Bagliniere, Nikolic, \& Evanno, 2013). Our findings were consistent with these expectations: stocking showed positive relationships with AR, PA and UNI in both gudgeons datasets, with significant effect sizes across datasets (see also Figure S1). Although stocking could be considered as rather anecdotal in minnows from the Viaur River (but see Figure S2), it was still retained as a possible driver of uniqueness, suggesting a long-lasting signature of introgression on patterns of genetic differentiation in this system (Perrier et al., 2013).

Two additional anthropogenic stressors were punctually found to influence patterns of genetic variability, the first of which was home-range sizes. Home ranges were delimited by upstream and downstream obstacles (weirs and dams) and were thus related to local levels of fragmentation. An increase in the size of home ranges may promote larger effective population sizes, thus balancing the influence of genetic drift and eventually increasing AR. A corollary is that a decrease in home-range size, implying an increase in the number of obstacles in the direct vicinity of populations, may result in restricted gene flow and genetic differentiation. We found a concomitant increase in home-range size and AR in gudgeons from the Viaur River, suggesting that populations from this highly fragmented river may suffer from higher genetic drift when obstacles restrain their home range. Although not retained in the final model, a similar trend was observed in minnows from the Viaur River (data not shown). Variations in home-range size did not show significant additive effect on other genetic metrics. In gudgeon datasets though, we found contrasting results as to the influence of home-range size on uniqueness as stocking increased. Interactions indeed indicated that uniqueness decreased or conversely increased with the increase in stocking probability in the Célé River and in the Viaur River, respectively. These unexpected outcomes are attributable to the variance in levels of fragmentation at stocking places: high probabilities of stocking were found in highly fragmented locations (low home-range sizes) in the Célé River, whereas it was the opposite in the Viaur River (Figure 4a,b). These interactions could thus be considered simple modalities of stocking influence on genetic uniqueness.

The last anthropogenic stressor found to covary with genetic variability was the percentage of urban areas in a $2-\mathrm{km}$ buffer around populations of minnows in the Célé River. The influence of 
urban land use on genetic uniqueness varied along the upstreamdownstream gradient. From low to moderate urban cover, uniqueness decreased along the upstream-downstream gradient, but conversely increased as urban land use increased (Figure 4c). This interaction resulted from the existence of a downstream gradient of urbanisation in the upstream half part of the main channel (demes 4-5-6, 9-10 and 13-14 in Figure 1b, the two latter showing an urban coverage of $100 \%$ ), counterbalancing the natural decrease in uniqueness along the first half of the upstream-downstream gradient. One can only speculate as to the origin of the increase in genetic differentiation in minnows inhabiting river stretches surrounded by urbanised areas. Urban land use may cause disproportionately large stresses in river networks, considering the restricted surface that it usually represents over total catchment areas (Allan, 2004). Increased runoff from impervious surface cover and bank artificialisation may critically affect hydrology, geomorphology and water quality of stream habitats, with serious impacts on algal, invertebrate and fish communities (Paul \& Meyer, 2001). The observed pattern in minnows from the Célé River may, for instance, result from a process of isolation-by-environment (Wang, 2013): populations in urbanised zones may experience reduced effective immigration from (and/or emigration to) neighbouring non-urbanised demes as a result of differential fitness or matching habitat choice in dispersers (phenotype-specific habitat selection; Edelaar, Siepielski, \& Clobert, 2008). This hypothesis implies eventual local adaptations to urbandriven environmental conditions in these populations (Brown, Gray, Hugues, \& Meador, 2005) and would require further investigations. Introgression might yet disrupt such patterns of local adaptation and affect the maintenance of urban populations (Marie et al., 2010).

\subsection{Multiple stressors in riverscape genetics}

By averaging predictors' unique contributions to genetic metrics across natural and anthropogenic thematic categories, we showed that the relative influences of natural features and human-induced stresses were primarily species-dependent: genetic variability was mostly explained by natural features (upstream-downstream gradients) in minnows and by anthropogenic stressors (stocking) in gudgeons, notably because the latter species experienced introgression in both rivers. It is surprising that fragmentation did not lead to more striking genetic signals as fragmentation is a rather old stress (notably in the Viaur River where weirs are up to 300 years old) and with a constant effect on populations. This may be explained by the relatively large effective population sizes of the two target species that may lessen the negative effects of reduced gene flow on genetic differentiation. Relative contributions also varied across genetic metrics, from AR, mostly driven by upstream-downstream gradients in accordance with the principle of DIGD, to genetic uniqueness, driven by complex additive and interactive effects among anthropogenic stressors, thus limiting any generalisation. Overall, natural features contributed 1.82 times more than anthropogenic features to genetic variability across species, rivers and genetic metrics. Whether this proportion could be used as a benchmark for future comparisons with other genetic studies based on a multiple-stressors approach is still to be determined. Nevertheless, quantifying the relative contribution of natural features and anthropogenic stressors on patterns of genetic diversity remains crucial, as it provides an interesting overview of ongoing processes in studied systems and could be used to further alert stakeholders to the various impacts of human activities, here accounting for about $35 \%$ of variance in spatial patterns of genetic diversity.

\subsection{Conclusions}

This study illustrated how a multiple-stressors approach, coupled with a fully explicit and conservative analytical framework, can help unveil the respective contributions of natural features and anthropogenic stressors to patterns of neutral genetic diversity and differentiation in wild populations across riverscape replicates (Short Bull et al., 2011). We showed that natural structure of networks and stocking were strong and consistent drivers of spatial patterns of genetic diversity in a predictable way, whereas the influence of other human activities may be much more difficult to predict over species and contexts.

\section{ACKNOWLEDGMENTS}

We thank all the people who helped us on the field, as well as Michèle Huet and Hugo Lainé for their help in laboratory. We also thank the Office Nationale de l'Eau et des Milieux Aquatiques (ONEMA) for financial support. Data used in this work were partly produced through the genotyping and sequencing facilities of ISEM (Institut des Sciences de l'Evolution-Montpellier) and Labex Centre Méditerranéen Environnement Biodiversité. The authors declare no conflict of interest.

\section{ORCID}

Jérôme G. Prunier (iD http://orcid.org/0000-0003-4110-2567

\section{REFERENCES}

Aiken, L. S., West, S. G., \& Reno, R. R. (1991). Multiple regression: Testing and interpreting interactions. Newbury Park, Calif, Sage Publications.

Aljanabi, S. M., \& Martinez, I. (1997). Universal and rapid salt-extraction of high quality genomic DNA for PCR-based techniques. Nucleic Acids Research, 25, 4692-4693.

Allan, J. D. (2004). Landscapes and riverscapes: The influence of land use on stream ecosystems. Annual Review of Ecology, Evolution, and Systematics, 35, 257-284.

Altermatt, F. (2013). Diversity in riverine metacommunities: A network perspective. Aquatic Ecology, 47, 365-377.

Andrew, R. L., Bernatchez, L., Bonin, A., Buerkle, C. A., Carstens, B. C., Emerson, B. C., ... Rieseberg, L. H. (2013). A road map for molecular ecology. Molecular Ecology, 22, 2605-2626.

Arlinghaus, R., Beardmore, B., Riepe, C., Meyerhoff, J., \& Pagel, T. (2014). Species-specific preferences of German recreational anglers for freshwater fishing experiences, with emphasis on the intrinsic 
utilities of fish stocking and wild fishes. Journal of Fish Biology, 85, 1843-1867.

Banks, S. C., Cary, G. J., Smith, A. L., Davies, I. D., Driscoll, D. A., Gill, A. M., ... Peakall, R. (2013). How does ecological disturbance influence genetic diversity? Trends in Ecology \& Evolution, 28, 670-679.

Barton, K. (2016). MuMIn: Multi-model inference. R package version 1.15.6. Retrieved from http://CRAN.R-project.org/package=MuMln

Bickham, J. W., Sandhu, S., Hebert, P. D. N., Chikhi, L., \& Athwal, R. (2000). Effects of chemical contaminants on genetic diversity in natural populations: Implications for biomonitoring and ecotoxicology. Mutation Research/Reviews in Mutation Research, 463, 33-51.

Blanchet, S., Rey, O., Etienne, R., Lek, S., \& Loot, G. (2010). Species-specific responses to landscape fragmentation: Implications for management strategies. Evolutionary Applications, 3, 291-304.

Bonnot, N., Morellet, N., Verheyden, H., Cargnelutti, B., Lourtet, B., Klein, F., \& Hewison, A. J. L. (2013). Habitat use under predation risk: Hunting, roads and human dwellings influence the spatial behaviour of roe deer. European Journal of Wildlife Research, 59, 185-193.

Borenstein, M. (Ed.) (2009). Introduction to meta-analysis. Chichester: John Wiley \& Sons.

Borics, G., Várbíró, G., \& Padisák, J. (2013). Disturbance and stress: Different meanings in ecological dynamics? Hydrobiologia, 711, 1-7.

Brown, R., Gray, R. H., Hugues, R. M., \& Meador, M. R. (2005). Effects of urbanization on stream ecosystems. Bethesda, MD: American Fisheries Society.

Burnham, K. P., \& Anderson, D. R. (2002). Model selection and multimodel inference: A practical information-theoretic approach (2nd ed.). New York, NY: Springer.

Caschili, S. (2010). ComplexNetGIS: A tool for the analysis of complex spatial networks. In Informatica e Pianificazione Urbana e Territoriale Vol 2, Las Casas G. Potrandolfi P. and Murgante B. Eds, Libria, Melfi, 233-242.

Champagnon, J., Elmberg, J., Guillemain, M., Gauthier-Clerc, M., \& Lebreton, J.-D. (2012). Conspecifics can be aliens too: A review of effects of restocking practices in vertebrates. Journal for Nature Conservation, 20, 231-241.

Christensen, M. R., Graham, M. D., Vinebrooke, R. D., Findlay, D. L., Paterson, M. J., \& Turner, M. A. (2006). Multiple anthropogenic stressors cause ecological surprises in boreal lakes. Global Change Biology, 12, 2316-2322.

Coleman, R. A., Weeks, A. R., \& Hoffmann, A. A. (2013). Balancing genetic uniqueness and genetic variation in determining conservation and translocation strategies: A comprehensive case study of threatened dwarf galaxias, Galaxiella pusilla (Mack) (Pisces: Galaxiidae). Molecular Ecology, 22, 1820-1835.

Conger, A. J. (1974). A revised definition for suppressor variables: A guide to their identification and interpretation. Educational and Psychological Measurement, 34, 35-46.

Connell, J. H., Hughes, T. P., \& Wallace, C. C. (1997). A 30-year study of coral abundance, recruitment, and disturbance at several scales in space and time. Ecological Monographs, 67, 461-488.

Côté, I. M., Darling, E. S., \& Brown, C. J. (2016). Interactions among ecosystem stressors and their importance in conservation. Proceedings of the Royal Society B: Biological Sciences, 283, 20152592. https://doi.org/10.1098/rspb.2015.2592

Dávalos, A., Nuzzo, V., \& Blossey, B. (2014). Demographic responses of rare forest plants to multiple stressors: The role of deer, invasive species and nutrients. Journal of Ecology, 102, 1222-1233.

Dormann, C. F., Elith, J., Bacher, S., Buchmann, C., Carl, G., Carré, G., ... Lautenbach, S. (2013). Collinearity: A review of methods to deal with it and a simulation study evaluating their performance. Ecography, 36, $27-46$.

Dudgeon, D., Arthington, A. H., Gessner, M. O., Kawabata, Z.-I., Knowler, D. J., Lévêque, C., ... Sullivan, C. A. (2006). Freshwater biodiversity:
Importance, threats, status and conservation challenges. Biological Reviews, 81, 163-182.

Edelaar, P., Siepielski, A. M., \& Clobert, J. (2008). Matching habitat choice causes directed gene flow: A neglected dimension in evolution and ecology. Evolution, 62, 2462-2472.

Fahrig, L. (2003). Effects of habitat fragmentation on biodiversity. Annual Review of Ecology, Evolution, and Systematics, 34, 487-515.

Faulks, L. K., Gilligan, D. M., \& Beheregaray, L. B. (2011). The role of anthropogenic vs. natural in-stream structures in determining connectivity and genetic diversity in an endangered freshwater fish, Macquarie perch (Macquaria australasica): Anthropogenic vs. natural instream structures in M. australasica. Evolutionary Applications, 4, 589601.

Finn, D. S., Bonada, N., Múrria, C., \& Hughes, J. M. (2011). Small but mighty: Headwaters are vital to stream network biodiversity at two levels of organization. Journal of the North American Benthological Society, 30, 963-980.

Folt, C. L., Chen, C. Y., Moore, M. V., \& Burnaford, J. (1999). Synergism and antagonism among multiple stressors. Limnology and Oceanography, 44, 864-877.

Frankham, R. (2010). Where are we in conservation genetics and where do we need to go? Conservation Genetics, 11, 661-663.

Grenier, R., Costedoat, C., Chappaz, R., \& Dubut, V. (2013). Two multiplexed sets of 21 and 18 microsatellites for Phoxinus phoxinus (L.) and Gobio gobio (L.) developed by cross-species amplification. European Journal of Wildlife Research, 59, 291-297.

Gurevitch, J., \& Padilla, D. K. (2004). Are invasive species a major cause of extinctions? Trends in Ecology \& Evolution, 19, 470-474.

Halpern, B. S., Selkoe, K. A., Micheli, F., \& Kappel, C. V. (2007). Evaluating and ranking the vulnerability of global marine ecosystems to anthropogenic threats. Conservation Biology, 21, 1301-1315.

Hand, B. K., Muhlfeld, C. C., Wade, A. A., Kovach, R. P., Whited, D. C., Narum, S. R., ... Luikart, G. (2016). Climate variables explain neutral and adaptive variation within salmonid metapopulations: The importance of replication in landscape genetics. Molecular Ecology, 25, 689-705.

Hedrick, P. W. (2005). A standardized genetic differentiation measure. Evolution, 59, 1633-1638.

Hoffmann, A. A., \& Willi, Y. (2008). Detecting genetic responses to environmental change. Nature Reviews Genetics, 9, 421-432.

Inostroza, P. A., Vera-Escalona, I., Wicht, A.-J., Krauss, M., Brack, W., \& Norf, H. (2016). Anthropogenic stressors shape genetic structure: Insights from a model freshwater population along a land use gradient. Environmental Science \& Technology, 50, 11346-11356.

Jombart, T., Devillard, S., \& Balloux, F. (2010). Discriminant analysis of principal components: A new method for the analysis of genetically structured populations. BMC Genetics, 11, 94.

Keenan, K., McGinnity, P., Cross, T. F., Crozier, W. W., \& Prodöhl, P. A. (2013). diveRsity: An R package for the estimation and exploration of population genetics parameters and their associated errors. Methods in Ecology and Evolution, 4, 782-788.

Keith, P., Persat, H., Feunteun, E., Adam, B., \& Geniez, M. (2011). Les Poissons d'eau douce de France. Paris and Mèze: Muséum National d'Histoire Naturelle and Publications Biotope.

Kottelat, M., \& Persat, H. (2005). The genus Gobio in France, with redescription of G. gobio and description of two new species (Teleostei: Cyprinidae). Cybium, 29, 211-234.

Laikre, L., Schwartz, M.K., Waples, R.S., Ryman, N., \& The GeM Working Group (2010). Compromising genetic diversity in the wild: Unmonitored large-scale release of plants and animals. Trends in Ecology \& Evolution, 25, 520-529.

Manel, S., Schwartz, M. K., Luikart, G., \& Taberlet, P. (2003). Landscape genetics: Combining landscape ecology and population genetics. Trends in Ecology \& Evolution, 18, 189-197. 
Marie, A. D., Bernatchez, L., \& Garant, D. (2010). Loss of genetic integrity correlates with stocking intensity in brook charr (Salvelinus fontinalis). Molecular Ecology, 19, 2025-2037.

McCarty, J. P. (2001). Ecological consequences of recent climate change. Conservation Biology, 15, 320-331.

Midway, S. R., Wagner, T., Tracy, B. H., Hogue, G. M., \& Starnes, W. C. (2015). Evaluating changes in stream fish species richness over a 50year time-period within a landscape context. Environmental Biology of Fishes, 98, 1295-1309.

Morrissey, M. B., \& de Kerckhove, D. T. (2009). The maintenance of genetic variation due to asymmetric gene flow in dendritic metapopulations. The American Naturalist, 174, 875-889.

Nacci, D. E., Gleason, T. R., \& Munns, W. R. (2002). Evolutionary and ecological effects of multi-generational exposures to anthropogenic stressors. Human and Ecological Risk Assessment, 8, 91-97.

Nakagawa, S., \& Cuthill, I. C. (2007). Effect size, confidence interval and statistical significance: A practical guide for biologists. Biological Reviews, 82, 591-605.

Narum, S. R., Buerkle, C. A., Davey, J. W., Miller, M. R., \& Hohenlohe, P. A. (2013). Genotyping-by-sequencing in ecological and conservation genomics. Molecular Ecology, 22, 2841-2847.

Nimon, K., Lewis, M., Kane, R., \& Haynes, R. M. (2008). An R package to compute commonality coefficients in the multiple regression case: An introduction to the package and a practical example. Behavior Research Methods, 40, 457-466.

Nimon, K., Oswald, F. L., \& Roberts, J. K. (2013). Interpreting regression effects. R package version 2.0-0. Retrieved from http://cran.r-project. org/web/packages/yhat/index.html

Nõges, P., Argillier, C., Borja, Á., Garmendia, J. M., Hanganu, J., Kodeš, V., ... Birk, S. (2016). Quantified biotic and abiotic responses to multiple stress in freshwater, marine and ground waters. Science of the Total Environment, 540, 43-52.

Paul, M. J., \& Meyer, J. L. (2001). Streams in the urban landscape. Annual Review of Ecology and Systematics, 32, 333-365.

Paulhus, D. L., Robins, R. W., Trzesniewski, K. H., \& Tracy, J. L. (2004). Two replicable suppressor situations in personality research. Multivariate Behavioral Research, 39, 303-328.

Paz-Vinas, I., \& Blanchet, S. (2015). Dendritic connectivity shapes spatial patterns of genetic diversity: A simulation-based study. Journal of Evolutionary Biology, 28, 986-994.

Paz-Vinas, I., Loot, G., Stevens, V. M., \& Blanchet, S. (2015). Evolutionary processes driving spatial patterns of intraspecific genetic diversity in river ecosystems. Molecular Ecology, 24, 4586-4604.

Paz-Vinas, I., Quéméré, E., Chikhi, L., Loot, G., \& Blanchet, S. (2013). The demographic history of populations experiencing asymmetric gene flow: Combining simulated and empirical data. Molecular Ecology, 22, 3279-3291.

Pearse, D. E., \& Crandall, K. A. (2004). Beyond FST: Analysis of population genetic data for conservation. Conservation Genetics, 5, 585-602.

Perrier, C., Guyomard, R., Bagliniere, J.-L., Nikolic, N., \& Evanno, G. (2013). Changes in the genetic structure of Atlantic salmon populations over four decades reveal substantial impacts of stocking and potential resiliency. Ecology and Evolution, 3, 2334-2349.

Pini, J., Planes, S., Rochel, E., Lecchini, D., \& Fauvelot, C. (2011). Genetic diversity loss associated to high mortality and environmental stress during the recruitment stage of a coral reef fish. Coral Reefs, 30, 399-404.

Pritchard, J. K., Stephens, M., \& Donnelly, P. (2000). Inference of population structure using multilocus genotype data. Genetics, 155, 945-959.

Prunier, J. G., Colyn, M., Legendre, X., \& Flamand, M.-C. (2017). Regression commonality analyses on hierarchical genetic distances. Ecography, 40, 001-014. https://doi.org/10.1111/ecog.02108

Prunier, J. G., Colyn, M., Legendre, X., Nimon, K. F., \& Flamand, M. C. (2015). Multicollinearity in spatial genetics: Separating the wheat from the chaff using commonality analyses. Molecular Ecology, 24, 263-283.

Prunier, J. G., Dubut, V., Chikhi, L., \& Blanchet, S. (2017). Contribution of spatial heterogeneity in effective population sizes to the variance in pairwise measures of genetic differentiation. Methods in Ecology and Evolution, https://doi.org/10.1111/2041-210X.12820, in press.

R Core Team (2014). R: A language and environment for statistical computing. R Foundation for Statistical Computing, Vienna, Austria. Retrieved from https://www.R-project.org/

Raeymaekers, J. A. M., Maes, G. E., Geldof, S., Hontis, I., Nackaerts, K., \& Volckaert, F. A. M. (2008). Modeling genetic connectivity in sticklebacks as a guideline for river restoration. Evolutionary Applications, 1, 475-488.

Ray-Mukherjee, J., Nimon, K., Mukherjee, S., Morris, D. W., Slotow, R., \& Hamer, M. (2014). Using commonality analysis in multiple regressions: A tool to decompose regression effects in the face of multicollinearity. Methods in Ecology and Evolution, 5, 320-328.

Reid, N. M., Proestou, D. A., Clark, B. W., Warren, W. C., Colbourne, J. K., Shaw, J. R., ... Whitehead, A. (2016). The genomic landscape of rapid repeated evolutionary adaptation to toxic pollution in wild fish. Science, 354, 1305-1308.

Ribeiro, R., \& Lopes, I. (2013). Contaminant driven genetic erosion and associated hypotheses on alleles loss, reduced population growth rate and increased susceptibility to future stressors: An essay. Ecotoxicology, 22, 889-899.

Rice, W. R. (1989). Analysing tables of statistical tests. Evolution, 43, 223-225.

Rogstad, S. H., Keane, B., \& Collier, M. H. (2003). Minisatellite DNA mutation rate in dandelions increases with leaf-tissue concentrations of $\mathrm{Cr}, \mathrm{Fe}, \mathrm{Mn}$, and Ni. Society of Environmental Toxicology and Chemistry, 22, 2093-2099.

Rousset, F. (2008). Dispersal estimation: Demystifying Moran's I. Heredity, 100, 231-232.

Shinn, C., Blanchet, S., Loot, G., Lek, S., \& Grenouillet, G. (2015). Phenotypic variation as an indicator of pesticide stress in gudgeon: Accounting for confounding factors in the wild. Science of the Total Environment, 538, 733-742.

Short Bull, R. A., Cushman, S. A., Mace, R., Chilton, T., Kendall, K. C., Landguth, E. L., ... Luikart, G. (2011). Why replication is important in landscape genetics: American black bear in the Rocky Mountains. Molecular Ecology, 20, 1092-1107.

Swindell, W. R. (2006). The association among gene expression responses to nine abiotic stress treatments in Arabidopsis thaliana. Genetics, 174, 1811-1824.

Szpiech, Z. A., Jakobsson, M., \& Rosenberg, N. A. (2008). ADZE: A rarefaction approach for counting alleles private to combinations of populations. Bioinformatics, 24, 2498-2504.

Thomaz, A. T., Christie, M. R., \& Knowles, L. L. (2016). The architecture of river networks can drive the evolutionary dynamics of aquatic populations. Evolution, 70, 731-739.

Van Oosterhout, C., Hutchinson, W. F., Wills, D. P. M., \& Shipley, P. (2004). MICRO-CHECKER: Software for identifying and correcting genotyping errors in microsatellite data. Molecular Ecology Notes, 4, 535-538.

Vandamme, S. G., Maes, G. E., Raeymaekers, J. A. M., Cottenie, K., Imsland, A. K., Hellemans, B., ... Volckaert, F. A. M. (2014). Regional environmental pressure influences population differentiation in turbot (Scophthalmus maximus). Molecular Ecology, 23, 618-636.

Vitousek, P. M., Mooney, H. A., Lubchenco, J., \& Melillo, J. M. (1997). Human domination of Earth's ecosystems. Science, 277, 494499.

Wang, I. J. (2013). Examining the full effects of landscape heterogeneity on spatial genetic variation: A multiple matrix regression approach for quantifying geographic and ecological isolation: Special section. Evolution, 67, 3403-3411. 
Zalapa, J. E., Brunet, J., \& Guries, R. P. (2010). The extent of hybridization and its impact on the genetic diversity and population structure of an invasive tree, Ulmus pumila (Ulmaceae). Evolutionary Applications, 3, 157-168.

\section{SUPPORTING INFORMATION}

Additional Supporting Information may be found online in the supporting information tab for this article.
How to cite this article: Prunier JG, Dubut V, Loot G, Tudesque $\mathrm{L}$, Blanchet $\mathrm{S}$. The relative contribution of river network structure and anthropogenic stressors to spatial patterns of genetic diversity in two freshwater fishes: A multiple-stressors approach. Freshwater Biol. 2018;63:6-21. https://doi.org/10.1111/fwb.13034 